Published in final edited form as:

Nat Clim Chang. 2017 August ; 7(8): 563-567. doi:10.1038/nclimate3345.

\title{
Importance of the Pre-Industrial Baseline in Determining the Likelihood of Exceeding the Paris Limits
}

\author{
Andrew P. Schurer ${ }^{1}$, Michael E. Mann ${ }^{2}$, Ed Hawkins ${ }^{3}$, Simon F. B. Tett ${ }^{1}$, and Gabriele C. \\ Hegerl ${ }^{1}$ \\ ${ }^{1}$ School of GeoSciences, University of Edinburgh, Crew Building, Alexander Crum Brown Road, \\ Edinburgh, EH9 3FF, United Kingdom \\ ${ }^{2}$ Dept. of Meteorology and Atmospheric Science \& Earth and Environmental Systems Institute, \\ Pennsylvania State University, State College, PA \\ ${ }^{3}$ NCAS-Climate, Dept. of Meteorology, University of Reading, Reading, RG6 6BB, United \\ Kingdom
}

\begin{abstract}
During the Paris Conference in 2015, nations of the world strengthened the United Nations Framework Convention on Climate Change by agreeing to holding "the increase in the global average temperature to well below $2^{\circ} \mathrm{C}$ above pre-industrial levels and pursuing efforts to limit the temperature increase to $1.5^{\circ} \mathrm{C}$ " 1 . However, "pre-industrial" was not defined. Here we investigate the implications of different choices of the pre-industrial baseline on the likelihood of exceeding these two temperature thresholds. We find that for the strongest mitigation scenario RCP2.6 and a medium scenario RCP4.5 the probability of exceeding the thresholds and timing of exceedance is highly dependent on the pre-industrial baseline, for example the probability of crossing $1.5^{\circ} \mathrm{C}$ by the end of the century under RCP2.6, varies from $61 \%$ to $88 \%$ depending on how the baseline is defined. In contrast, in the scenario with no mitigation, RCP8.5, both thresholds will almost certainly be exceeded by the middle of the century with the definition of the pre-industrial baseline of less importance. Allowable carbon emissions for threshold stabilisation are similarly highly dependent on the pre-industrial baseline. For stabilisation at $2^{\circ} \mathrm{C}$, allowable emissions decrease by as much as $40 \%$ when earlier than 19th century climates are considered as a baseline.
\end{abstract}

In the Fifth Assessment Report (AR5) of the Intergovernmental Panel on Climate Change (IPCC), the likelihood of global mean temperatures exceeding $1.5^{\circ} \mathrm{C}$ and $2{ }^{\circ} \mathrm{C}$ above 1850-1900 levels was estimated2,3. No estimates were provided, however, for a true "preindustrial" baseline in this context. Given that the industrial revolution and concomitant increase in greenhouse gases (GHG) was well underway by the late- $18^{\text {th }}$ century4,5 the late- $19^{\text {th }}$ century temperatures do not provide an accurate "pre-industrial" baseline as

\footnotetext{
Users may view, print, copy, and download text and data-mine the content in such documents, for the purposes of academic research, subject always to the full Conditions of use:http://www.nature.com/authors/editorial_policies/license.html\#terms

Correspondence and request for material should be directed to Andrew Schurer, a.schurer@ed.ac.uk.

Contributions:

A.S. and M.E.M. conceived the initial idea. A.S. performed the analysis. All contributed to the writing, methodology and analysis strategy.
} 
specified by the Paris agreement1. Unfortunately, the estimation of pre-industrial temperature is far from straightforward6. GHG concentrations have been increasing since industrialization began around 1750, and are likely to have impacted global temperatures7,8. Consequently, estimates of a temperature baseline prior to the industrial revolution would be desirable9,6. However very few instrumental measurements of temperature exist, prior to the $19^{\text {th }}$ century, and these are concentrated in the Northern Hemisphere10. To further complicate matters, natural fluctuations in global temperature are ever-present, leading to multi-decadal and longer-term changes throughout the last-millennium11,12,13,14, implying that there is no single value for pre-industrial global mean temperature. Some of this variability is linked to natural forcings, particularly volcanic eruptions, and variations in GHG concentration, such as the small drop in 16005,15 . In this article, we estimate probabilities for exceeding key temperature thresholds, under different emission scenarios, including the impact of differing assumptions regarding the pre-industrial temperature baseline.

To determine the effect of the pre-industrial baseline on the probability of exceeding projected temperature thresholds, we use model simulations performed as part of the Coupled Model Intercomparison Project Phase 5 (CMIP5)16. We use historical simulations and projections from three different future representative concentration pathways (RCPs), namely: RCP2.6, RCP4.5 and RCP8.5 to calculate continuous global temperature time series from 1861-2100. We employ a global blend of simulated sea surface temperatures and surface air temperature (SATs) 17 (Figure 1). In contrast to other studies which just use SATs18,2, this allows the most rigorous and unbiased comparison to current blended observational datasets 19,20,21, which we have assumed will be those used to determine if a temperature threshold has been reached in the future. Following the approach of Joshi et al18 we first calculate anomalies from 1986-2005 (as used by IPCC AR52,3), and add an estimate of the difference between this period and pre-industrial. To estimate the latter, we combine warming over the 1850-2005 period, calculated from observations, with an estimate of warming prior to 1850 . Similar analyses have been found to be particularly sensitive to the choice of anomaly period 22 , and we choose this method because tying projections to more recent observations will reduce the impact of the uncertainty in past radiative forcing, since we do not rely on modelled warming prior to 1986. We define threshold exceedance based on 5-year annual mean temperatures (see methods), in order to avoid temporary early threshold exceedances due to internal variability, such as that linked to large El-Nino events.

If we assume 1850-1900 can be used as a pre-industrial baseline (i.e. warming before $1850-1900$ has been negligible) it is almost certain that $2^{\circ} \mathrm{C}$ will be exceeded in the high future emissions scenario (RCP8.5), very likely by the middle of the century $(\mathrm{p}=0.85)$, with a median estimate of a $3.9^{\circ} \mathrm{C}$ increase by the end of the century (Fig. 1). In the scenario with moderate mitigation (RCP4.5) it is still unlikely that the temperature increase can be limited to below $2^{\circ} \mathrm{C}(\mathrm{p}<0.2)$, with a median estimate warming of $2.3^{\circ} \mathrm{C}$ by the end of the century. It is only in the pathway with strong mitigation ( $\mathrm{RCP} 2.6)$ where preventing a temperature rise above $2^{\circ} \mathrm{C}$ becomes probable $(\mathrm{p}=0.75)$ and holding temperatures below $1.5^{\circ} \mathrm{C}$ possible $(\mathrm{p}=0.40)$. These projected temperatures are slightly lower than those presented in IPCC AR52. This is because the use of blended temperatures instead of global mean SATs results in about 4-10\% less warming 17 (see supplement). Note that these estimates rely on the 
model spread encapsulating the true response, and uncertainties would be somewhat larger if the uncertainty in transient climate response beyond the model range was included 2 .

How large an impact could choosing a pre-industrial period before 1850-1900 have on these probabilities, given the observed fluctuations in temperature throughout the last millennium and beyond? A number of model simulations now exist covering the last millennium and these can be used to calculate global temperatures over different periods between 1401 and 1850 , to determine how much warmer (or colder) the late- $19^{\text {th }}$ century is to a "true" preindustrial baseline. We concentrate on the period 1401-1800, as it pre-dates the major anthropogenic increase in GHGs, coincides with a diverse range of natural (volcanic and solar) forcing5 and is a period where reconstructions agree reasonably well with each other, and with model simulations,13,23 and are based on the most data13,11. This therefore leads to greater confidence in the model simulations. In addition, it is also the period where we have most model data and further back in time orbital forcing begins to diverge from that of present day, making earlier periods less suitable.

In total, spatially complete blended global temperatures from 23 simulations, from 7 different models, were analysed with the means of each model for different segments of the period $1401-1800$ found to be cooler than the late- $19^{\text {th }}$ century baseline $(1850-1900)$ by $0.03^{\circ} \mathrm{C}$ to $0.19^{\circ} \mathrm{C}$ (multi-model mean of $0.09^{\circ} \mathrm{C}$, fig $2 \mathrm{~b}$ ). In these simulations, and in temperature reconstructions of the past millennium 11,12 , there is considerable centennial variability. Some periods, such as the $16^{\text {th }}$ century, are of comparable warmth to the late- $19^{\text {th }}$ century, while other periods have a multi-model mean nearly $0.2^{\circ} \mathrm{C}$ cooler.

Simulations from 3 models run with single-forcings (fig 2c-e) show that the major cause of variations in pre-industrial temperature between centuries is a varying frequency of volcanic eruptions; with a consistent cooling due to lower $\mathrm{CO}_{2}$ levels and a smaller solar influence consistent with a small attributed response to solar forcing over the Northern Hemisphere15. Choosing any particular sub-interval over the past millennium to define pre-industrial temperatures thus involves a certain level of subjectivity. To quantify this we calculate a combined distribution of 100-year periods from 1401-1800 from each of the 7 models (see methods; fig S7 and fig 3), resulting in a 5-95\% range of -0.02 to $0.21^{\circ} \mathrm{C}$. Several studies have identified that the cooling response to very large volcanic eruptions in model simulations exceeds the response estimated in many proxy temperature reconstructions 7,13. While there is ongoing debate in the literature over the cause 24,25 , this remains a source of uncertainty when analysing model simulations during the volcanically active $17^{\text {th }}-19^{\text {th }}$ centuries. Also, the magnitude of past solar forcing is uncertain, although most likely small15,5, as are estimates of early industrial aerosols and land use. Hence, the true uncertainties are almost certainly larger than shown in figure 2 .

Another way to approach the question of an appropriate pre-industrial baseline is to ignore natural forced variability and consider how much warmer 1850-1900 is due to just anthropogenic forcing. To estimate this we use climate models driven only with changes in GHG concentrations (fig 2c). The calculated mean difference between 1850-1900 and the period 1401-1800 in different models ranges from 0.10 to $0.18{ }^{\circ} \mathrm{C}$ (multi-model mean $0.13{ }^{\circ} \mathrm{C}$, see supplement for more details), with some dependence on the period analysed due 
to the dip in GHGs in 1600. This yields an estimate of warming to $1850-1900$ with a 5-95\% range of 0.02 to $0.20^{\circ} \mathrm{C}$. This approach, however, assumes that the increase in $\mathrm{CO}_{2}$ since the Little Ice Ages (LIA) is largely anthropogenic in origin. As the cause of the $\mathrm{LIA} \mathrm{CO}_{2}$ drop is unknown, this is far from clear, although supported by a previous modelling study that found only a small contribution from natural forcings to the $18^{\text {th }}$ and $19^{\text {th }} \mathrm{GHG}$ concentration increase4. Implicit in estimating pre-industrial temperatures based on GHGs alone is also the

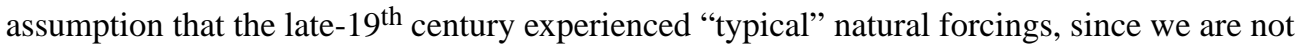
accounting for differences in natural forcing. It also does not account for changes in other potential anthropogenic forcings, particularly a cooling from early anthropogenic aerosols, which could have been substantial26 but is highly uncertain 27,28 , as is a potential radiative effect of early land-use change29,30.

The estimates obtained above, suggest that depending on the definition of pre-industrial and the model used, the late- $19^{\text {th }}$ century could provide a reasonable estimate of the preindustrial temperature baseline or alternatively this choice could underestimate the true warming since pre-industrial by as much as $0.2^{\circ} \mathrm{C}$. This is a slightly higher range than that calculated by Hawkins et al (H17)6 (see fig 3) which was based on choosing a relatively low volcanic period, namely 1720-1800. It should be noted that these values are specific to the period 1401-1800 and the range of possible pre-industrial temperatures is likely to increase if periods further back in time are analysed. In particular, periods during the medieval climate anomaly at the start of the last millennium, may have warmer temperatures than the late- $19^{\text {th }}$ century, particularly in the $11^{\text {th }}$ and $12^{\text {th }}$ century. In models this is due to a combination of orbital forcing and solar forcing with reduced volcanic forcing (figure S6) and this should increase even more further back in time11.

To calculate the effect that our new estimated range of additional warming since preindustrial could have on the likelihood of crossing key (i.e. $1.5^{\circ} \mathrm{C}$ and $2^{\circ} \mathrm{C}$ ) thresholds under different scenarios, we re-calculate the probabilities with a wide, but plausible range of additional pre-industrial warming, covered by our 5-95\% distributions (approximately 0 to $0.2^{\circ} \mathrm{C}$ ), with results shown in Figure $3 \& 4$. The results highlight the particular importance of the definition of pre-industrial temperature to the exceedance likelihoods for the strong mitigation scenario RCP2.6. For this scenario the probability of exceeding the $1.5^{\circ} \mathrm{C}$ threshold increases from $61 \%$ to $88 \%$ if the late- $19^{\text {th }}$ century is assumed to be $0.2^{\circ} \mathrm{C}$ warmer than the true pre-industrial. The probability of exceeding $2^{\circ} \mathrm{C}$ increases from $25 \%$ to $30 \%$ under RCP2.6 and from $80 \%$ to $88 \%$ under RCP4.5. The choice of pre-industrial period also effects the time of threshold crossing with the greater assumed pre-late- $19^{\text {th }}$ century warming leading to earlier reaching of thresholds (Fig 4). This effect is larger under scenarios with more mitigation because the associated rate of temperature change is smaller (Fig 3). For RCP4.5, for example, the year in which the $50 \%$ probability for $2^{\circ} \mathrm{C}$ warming is crossed is reduced from 2059 to 2048 if $0.2^{\circ} \mathrm{C}$ of pre-late- $19^{\text {th }}$ century warming is assumed.

It is possible to weight model projections based on the agreement between the models simulated past temperatures and observed temperature. Results where each model is weighted based on its agreement with observations from 1865-2005 are shown in the supplement (figs S11-13). The probability of avoiding $1.5^{\circ} \mathrm{C}$ and the importance of the preindustrial baseline is unaffected by the weighting. Weighting does however reduce the 
uncertainty of the projections, and thus the probability of avoiding $2^{\circ} \mathrm{C}$ in both the RCP2.6 and RCP4.5 scenarios is reduced.

The relatively small early warming can also have dramatic impacts on cumulative carbon budgets. In the most recent IPCC report 2 the total carbon budget allowed to avoid exceeding $1.5^{\circ} \mathrm{C}$ and $2^{\circ} \mathrm{C}$ was given as the amount of carbon emissions since 1870 which would lead to a warming relative to an 1861-1880 baseline. If we assume linearity these values will still hold for temperature increases relative to a true pre-industrial baseline provided that the carbon emissions are also re-calculated from a true pre-industrial period. If instead we wish to keep temperature beneath a threshold relative to a pre-industrial baseline but use the existing estimates for carbon emissions since 1870, then the carbon budget must be lowered accordingly. The IPCC estimated that that there is a 50\% likelihood of keeping temperature to a $2^{\circ} \mathrm{C}$ threshold (relative to $1861-1880$ ) if $1210 \mathrm{GTC}$ is emitted since 18702 (which equates to $605 \mathrm{GTC}$ per degree warming). If non- $\mathrm{CO}_{2}$ forcings, are also taken into account, under the RCP2.6 scenario, the allowed emissions of carbon reduce further to 820GTC. Given that the IPCC estimates that 515GTC had been emitted up until 2011 (since 1870) this leaves 305GTC still to be emitted. But, assuming linearity, if a warming of $0.1^{\circ} \mathrm{C}$ had already occurred due to $\mathrm{CO}_{2}$ increases by 1861-1880, then around 60GTC of the budget would have already been used. This corresponds to roughly $20 \%$ of the budget still remaining (in 2011), and approximately $40 \%$ if the early warming was as much as $0.2^{\circ} \mathrm{C}$. The corresponding fractions of the remaining budget are likely to be even larger for a $1.5^{\circ} \mathrm{C}$ target.

Despite remaining uncertainties there are at least two robust implications of our findings. Firstly, mitigation targets based on the use of a late- $19^{\text {th }}$ century baseline are probably overly optimistic and potentially substantially underestimate the reductions in carbon emissions necessary to avoid $1.5^{\circ} \mathrm{C}$ or $2^{\circ} \mathrm{C}$ warming of the planet relative to pre-industrial. Secondly, while pre-industrial temperature remains poorly defined, a range of different answers can be calculated for the estimated likelihood of global temperatures reaching certain temperature values. We would therefore recommend that a consensus be reached as to what is meant by pre-industrial temperatures to reduce the chance of conclusions which appear contradictory, being reached by different studies and to allow for a more clearly defined framework for policymakers and stakeholders6.

\section{Methods}

In order to investigate global mean temperatures during the historic and future period, we use CMIP5 model projections for the three RCP scenarios (RCP2.6, RCP4.5 and RCP8.5), with anomalies taken over the period 1986-2005. Modelled surface temperature values are calculated from a blend of SATs and SSTs following Cowtan et al 201517 for total global coverage. Previously, analyses have typically used just global SATs2. Our choice to use blended temperatures is motivated by the current use of blended observational datasets, which will likely be those used to determine if a temperature threshold has been reached.

To estimate the temperature change since pre-industrial (TEMP pre-industrial , we follow equation 1 : 


$$
\mathrm{TEMP}_{\text {pre- }} \text { industrial }=\mathrm{TEMP}_{1986-2005}+\mathrm{PRE}+\mathrm{IND}
$$

Where blended temperature since a true-preindustrial baseline (TEMP $\mathrm{pre-industrial}_{\text {) }}$, is calculated by first taking anomalies from 1986-2005 (TEMP ${ }_{1986-2005}$ ), adding values for observed warming from 1850-1900 to 1986-2005 (IND) and then an estimate for the difference between 1850-1900 and the true-preindustrial baseline (PRE). The IPCC AR5 report estimated a warming of $0.61^{\circ}$ for IND, based on the HadCRUT4 dataset10. Given that we are calculating global mean temperature with full coverage we instead use an estimate calculated using the Cowtan and Way 19 observational dataset which has used the same data as HadCRUT4 but has been infilled using kriging. This gives a value of $0.65^{\circ} \mathrm{C}$. To account for the uncertainty in IND, we calculate an estimate from the 100 published ensemble members19. HadCRUT4 and Cowtan and Way show less warming over this period then several other datasets20,31, for example in the Berkeley Earth global land and sea data32 it is $0.71^{\circ} \mathrm{C} 6$. Using different observational datasets could therefore result in earlier threshold exceedances.

To estimate values for PRE we use model simulations from seven different models (see supplement for more details) and calculate global temperature as a blend of surface air temperature and sea surface temperature following Cowtan et al 201517. We use model simulations which have been forced with all available forcings and those which only consider single forcings at a time. To calculate values of 100 year mean temperatures we use all possible model simulations. A distribution for all the 100-year values within the period 1401-1800 is calculated using all available model simulation (see supplement tables S2-4 for more details). Models providing multiple ensemble members are weighted down so that each model contributes equally to the distribution. The final distribution is then calculated using kernel density estimation.

To determine the sensitivity of our results to the way that the pre-industrial anomalies are calculated, we modify equation 1 :

$$
\mathrm{TEMP}_{\text {pre- industrial }}=\mathrm{TEMP}_{1861-}{ }_{1900}+\mathrm{PRE}+\mathrm{Tdiff}
$$

Here TEMP pre-industrial is calculated from model simulations with anomalies from 1861-1900 (note that 1861 was used as a start date rather than 1850 because some model simulations only start in 1861). Similar to eqn. 1 we add PRE, which is the temperature difference from pre-industrial to 1850-1900. To account for the slight difference between the model simulations anomaly period (1861-1900) and the period for which PRE applies (1850-1900) we add on a factor, Tdiff, which is the observed temperature difference between 1861-1900 and 1850-1900, accounting for observational uncertainty, in the same way as for IND in Eqn. 1. We favour the first method (Eqn. 1) because we consider observed warming from 1850-1900 to be more reliable in observations than in models, due to uncertainties in radiative forcing and the models response to them. Our conclusions are not particularly sensitive to this choice (see supplement). 
The likelihood for the mean temperature in 2080-2100 above a pre-industrial background for each of the RCP scenarios is calculated from the full blended global mean temperature for each model simulation. By accounting for the observational uncertainty in IND we calculate a likelihood distribution for each model simulation. To combine these distributions into one joint-distribution a weighted mean over all available model simulations is calculated, where the weights are set to account for the number of ensemble members each model has, so that each model counts equally. The median and 5-95\% range is then calculated from the resultant distribution as is the likelihood of temperatures exceeding the $1.5^{\circ} \mathrm{C}$ and $2^{\circ} \mathrm{C}$ limits.

To estimate the threshold crossing times, first the global annual mean temperatures are smoothed by a 5-year running mean and for every year a joint probability distribution is calculated from each individual model simulation, accounting for observational uncertainty in IND. A threshold is said to have been crossed in the first year when 50\% of the model distribution (weighted by number of ensemble members) is above the limit.

The authors declare that all data that support the findings in the main article are available. Code and date for the blended temperatures are available via Kevin Cowtan (http://wwwusers.york.ac.uk/ kdc3/papers/robust2015/). The rest of the code and further data is available on the University of Edinburgh datashare (http://datashare.is.ed.ac.uk/handle/ 10283/2720) with the identifier "doi:XXXXXXX". All data and code that support the figures in the Supplementary information are available from the corresponding author on request.

\section{Supplementary Material}

Refer to Web version on PubMed Central for supplementary material.

\section{Acknowledgements}

We thank Kevin Cowtan for making his code and results available and for help in their use and Steven Phipps for CSIRO-Mk3L-1.2 model data. A.S., G.H. and S.T. were supported by the ERC funded project TITAN (EC-320691) and A.S. and G.H. by NERC under the Belmont forum, grant PacMedy (NE/P006752/1), G.H. and S.T. were supported by NCAS (R8/H12/83/029) and GH was further funded by the Wolfson Foundation and the Royal Society as a Royal Society Wolfson Research Merit Award (WM130060) holder. E.H. and GH was supported by the NERC-funded SMURPHS project (NE/N006038/1) and EH by a NERC Fellowship (NE/I020792/1) and NCAS. M.E.M. acknowledges support for this work from the P2C2 program of the National Science Foundation (grant ATM-1446329). We acknowledge the World Climate Research Programme's Working Group on Coupled Modelling, which is responsible for CMIP, the climate modelling groups for producing and making available their model output, the U.S. Department of Energy's Program for Climate Model Diagnosis and Intercomparison, and the Global Organization for Earth System Science Portals for Earth System Science Portals. We thank Fortunat Joos for discussion of causes of the $\mathrm{CO} 2$ increase since the Little Ice Age.

\section{References}

1. Adoption of the Paris Agreement FCCC/CP/2015/10/Add.1. UNFCCC; 2015.

2. Collins M, et al. Long-term Climate Change: Projections, Commitments and Irreversibility. Clim Chang 2013 Phys Sci Basis Contrib Work Gr I to Fifth Assess Rep Intergov Panel Clim Chang. 2013; :1029-1136. DOI: 10.1017/CBO9781107415324.024

3. Kirtman B, et al. Near-term Climate Change: Projections and Predictability. Clim Chang 2013 Phys Sci Basis Contrib Work Gr I to Fifth Assess Rep Intergov Panel Clim Chang. 2013:953-1028. 
4. Gerber $S$, et al. Constraining temperature variations over the last millennium by comparing simulated and observed atmospheric CO 2. Climate Dynamics. 2003; :281-299. DOI: 10.1007/ s00382-002-0270-8

5. Schmidt, Ga, et al. Climate forcing reconstructions for use in PMIP simulations of the Last Millennium (v1.1). Geosci Model Dev. 2012; 5:185-191.

6. Hawkins, Ed, Ortega, Pablo, Schurer, Andrew, Suckling, Emma, Hegerl, Gabi, Jones, Phil, Josh, Manoji, Masson-Delmotte, Valerie, Mignot, Juliette, Osborn, Timothy J., Thorne, Peter, et al. Estimating changes in global temperature since the pre-industrial period. Bull Am Meteorol Soc. 2016

7. Schurer AP, Hegerl GC, Mann ME, Tett SFB, Phipps SJ. Separating Forced from Chaotic Climate Variability over the Past Millennium. J Clim. 2013; 26:6954-6973.

8. Abram NJ, et al. Early onset of industrial-era warming across the oceans and continents. Nature. 2016; 536:411-418. [PubMed: 27558063]

9. Mann ME. False Hope. Sci Am. 2014; 310:78-81.

10. Hartmann, DJ., et al. Climate Change 2013: The Physical Science Basis. Contribution of Working Group I to the Fifth Assessment Report of the Intergovernmental Panel on Climate Change. Stocker, TF.Qin, D.Plattner, G-K.Tignor, M.SK, A.Boschung, J.Nauels, A.Xia, Y.B, V., M, PM., editors. Cambridge University Press; Cambridge: 2013. p. 159-254.

11. Mann ME, et al. Proxy-based reconstructions of hemispheric and global surface temperature variations over the past two millennia. Proc Natl Acad Sci U S A. 2008; 105:13252-7. [PubMed: 18765811]

12. Ahmed M, et al. Continental-scale temperature variability during the past two millennia. Nat Geosci. 2013; 6:339-346.

13. Masson-Delmotte V, et al. Information from Paleoclimate Archives. Clim Chang 2013 Phys Sci Basis Contrib Work Gr I to Fifth Assess Rep Intergov Panel Clim Chang. 2013:383-464.

14. Hasselmann K. Stochastic climate models Part I. Theory. Tellus. 1976; 28:473-485.

15. Schurer AP, Tett SFB, Hegerl GC. Small influence of solar variability on climate over the past millennium. Nat Geosci. 2014; 7

16. Taylor KE, Stouffer RJ, Meehl GA. An Overview of CMIP5 and the Experiment Design. Bull Am Meteorol Soc. 2012; 93:485-498.

17. Cowtan K, et al. Robust comparison of climate models with observations using blended land air and ocean sea surface temperatures. Geophys Res Lett. 2015; 42:6526-6534.

18. Joshi M, Hawkins E, Sutton R, Lowe J, Frame D. Projections of when temperature change will exceed $2{ }^{\circ} \mathrm{C}$ above pre-industrial levels. Nat Clim Chang. 2011; 1:407-412.

19. Cowtan K, Way RG. Coverage bias in the HadCRUT4 temperature series and its impact on recent temperature trends. Q J R Meteorol Soc. 2014; 140:1935-1944.

20. Hansen J, Ruedy R, Sato M, Lo K. GLOBAL SURFACE TEMPERATURE CHANGE. Rev Geophys. 2010; 48 RG4004.

21. Morice CP, Kennedy JJ, Rayner NA, Jones PD. Quantifying uncertainties in global and regional temperature change using an ensemble of observational estimates: The HadCRUT4 data set. J Geophys Res Atmos. 2012; 117 n/a-n/a.

22. Hawkins E, Sutton R, Hawkins E, Sutton R. Connecting Climate Model Projections of Global Temperature Change with the Real World. Bull Am Meteorol Soc. 2016; 97:963-980.

23. Schurer AP, Hegerl GC, Mann ME, Tett SFB, Phipps SJ. Separating forced from chaotic climate variability over the past millennium. J Clim. 2013; 26

24. Mann ME, Rutherford S, Schurer A, Tett SFB, Fuentes JD. Discrepancies between the modeled and proxy-reconstructed response to volcanic forcing over the past millennium: Implications and possible mechanisms. J Geophys Res Atmos. 2013; 118:7617-7627.

25. D'Arrigo R, Wilson R, Anchukaitis KJ. Volcanic cooling signal in tree ring temperature records for the past millennium. J Geophys Res Atmos. 2013; 118:9000-9010.

26. Carslaw KS, et al. Large contribution of natural aerosols to uncertainty in indirect forcing. Nature. 2013; 503:67-71. [PubMed: 24201280] 
27. Jones GS, Stott PA, Mitchell JFB. Uncertainties in the attribution of greenhouse gas warming and implications for climate prediction. 2016; doi: 10.1002/2015JD024337

28. Stevens B, Stevens B. Rethinking the Lower Bound on Aerosol Radiative Forcing. J Clim. 2015; 28:4794-4819.

29. Pongratz J, Reick C, Raddatz T, Claussen M. A reconstruction of global agricultural areas and land cover for the last millennium. Global Biogeochem Cycles. 2008; 22 n/a-n/a.

30. Kaplan JO, et al. Holocene carbon emissions as a result of anthropogenic land cover change. The Holocene. 2010; 21:775-791.

31. Karl TR, et al. Possible artifacts of data biases in the recent global surface warming hiatus. Science (80-. ). 2015; 348:1469-1472.

32. Rohde R, et al. A New Estimate of the Average Earth Surface Land Temperature Spanning 1753 to 2011. Geoinformatics \& Geostatistics: An Overview. 2013; 1 


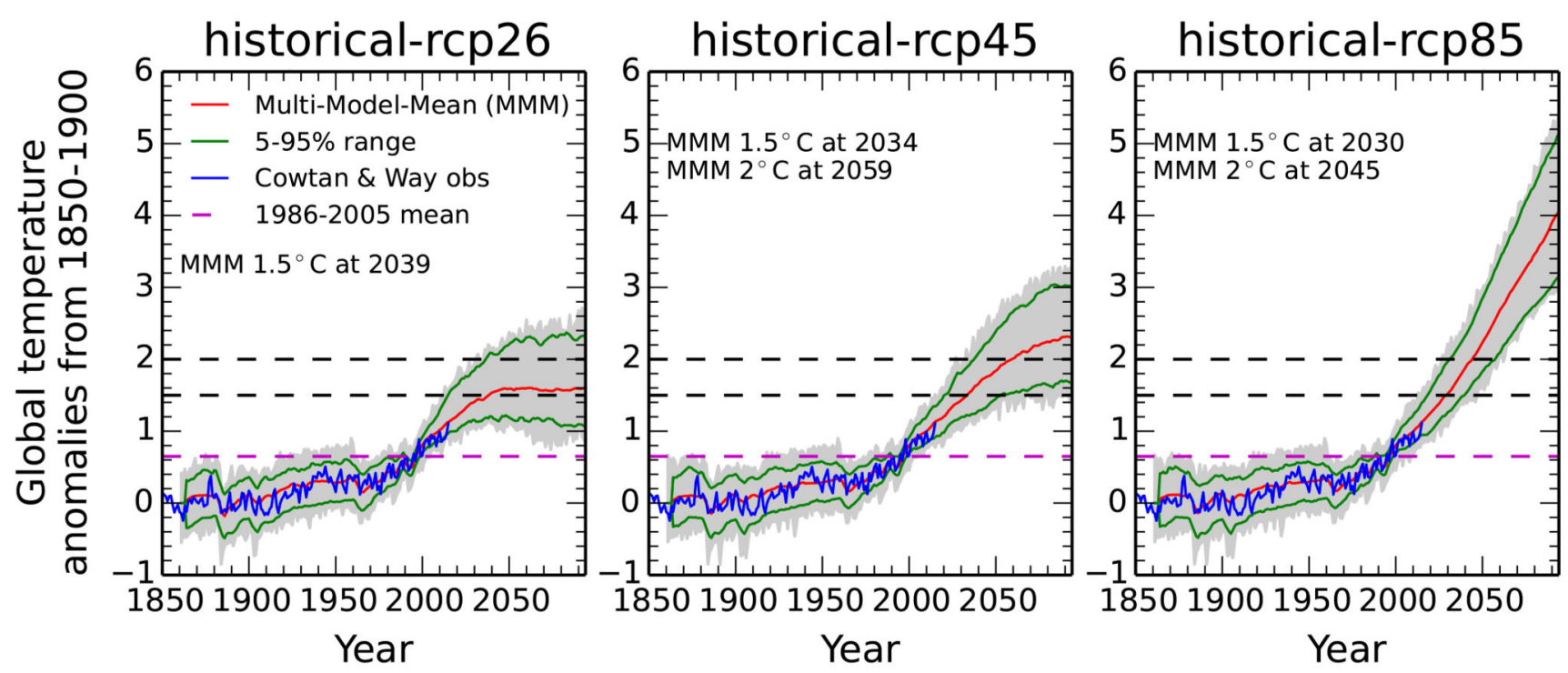

Fig 1. Historical data and future projections for global mean temperature.

Annual global mean temperature for observations 17 (blue) and model simulation range (grey), anomalies first calculated for 1986-2005 and then observed warming since 1850-1900 (0.6517 - purple dashed line) has been added. Model mean (red) and 5-95\% range (green) of the probability distribution from the model simulations smoothed by a 5year running mean for 3 different future scenarios. Year when the median of the model distribution relative to $1850-1900$ crosses the $1.5^{\circ} \mathrm{C}$ and $2^{\circ} \mathrm{C}$ thresholds are given in text. 
Temperature difference between pre-industrial and 1850-1900

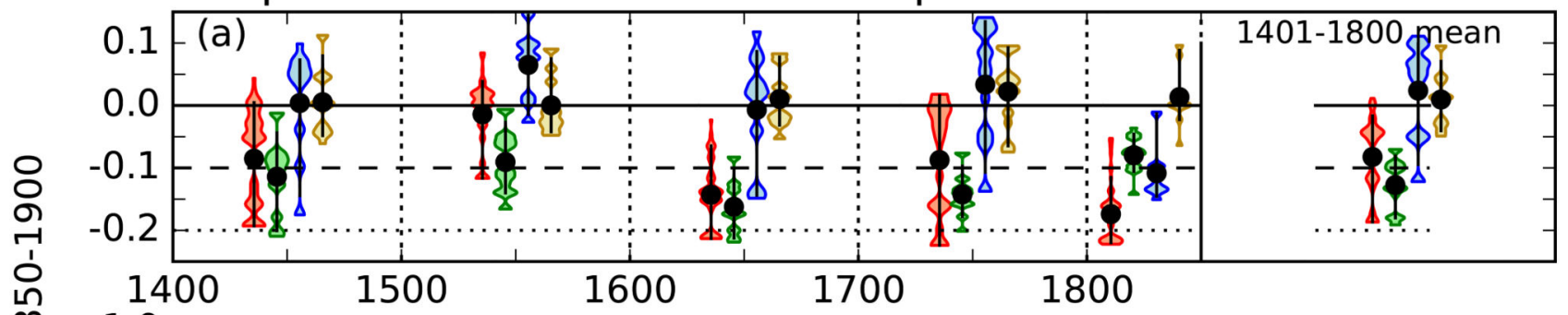

o

(4)

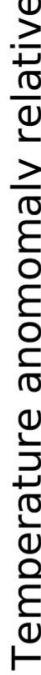
1.0
0.5
(b) All forced (b) All forced

0.0

$-0.5$

$-1.0$

0.75 (c) GHG

0.25

$-0.25$

$-2-1$

0.5 (d) Volcanic

$0.0=0.5$

0.5 (e) Solar

$0.0=$

1400

1500

1600

1700
Year

Fig 2. Model simulated difference in global mean temperature between different pre-industrial periods and 1850-1900.

a) Range of ensemble means for different models, and for different forcing combinations. Model distribution fitted with a Kernel Density Estimate (violin plot) - red: All forcings combined; green: greenhouse gas forcing only, blue: volcanic forcing only, yellow: solar forcing only. Model mean: circle, 10-90\% model range: bar. Differences refer to the mean of the period enclosed by the dotted lines; except on far right where they are means for the full period 1401-1800 (relative to 1850 to 1900). b)-e) Model means for different forcing combinations, colours ensemble means for individual models, black line - mean over all models. 


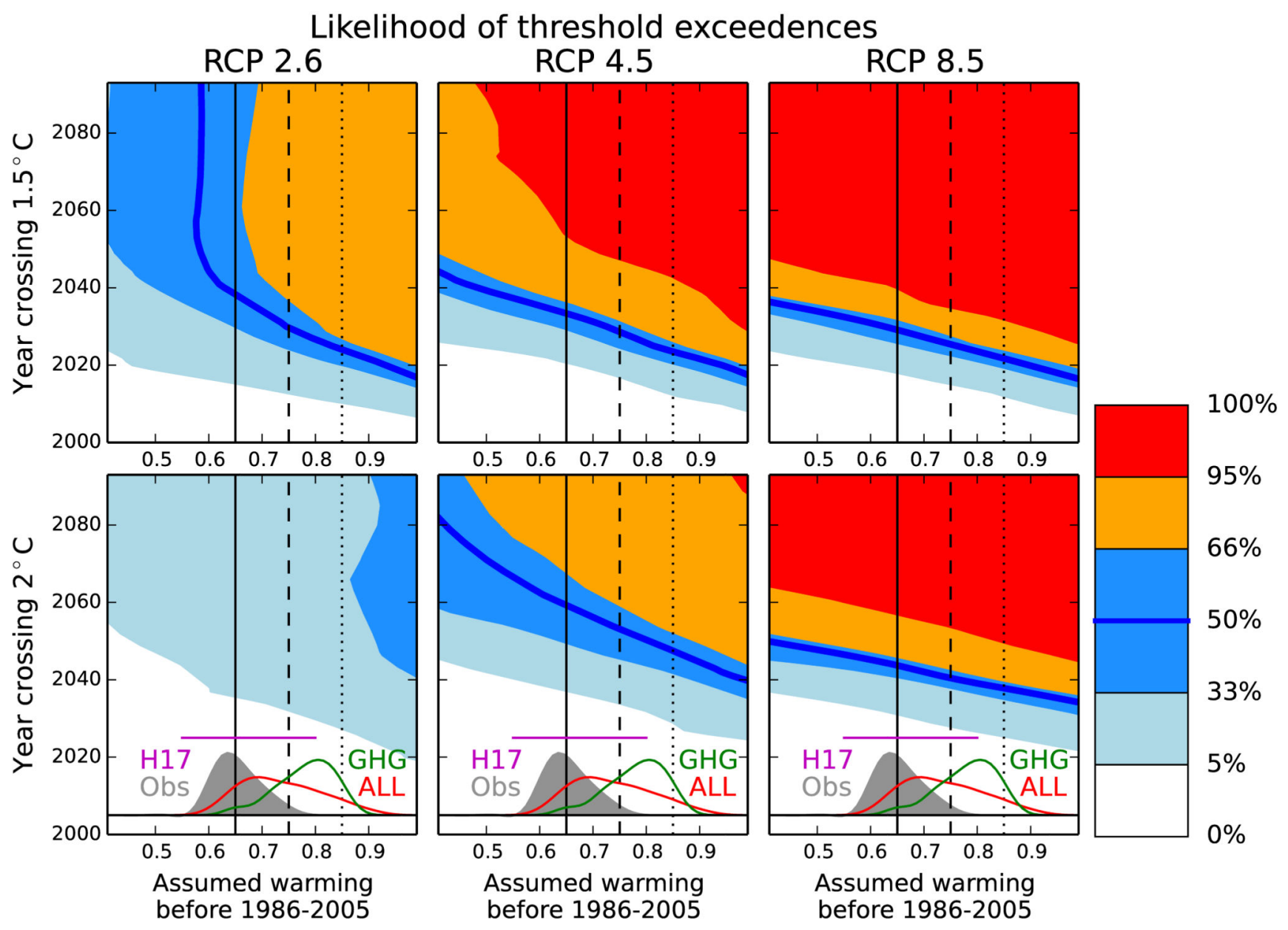

Fig 3. Probability of exceeding temperature threshold for different assumed preindustrial baselines.

Probabilities for exceeding a particular global mean temperature threshold in any given year are given [\%], smoothed by a 30-year Lowess filter for clarity (un-filtered version in supplement). Vertical lines indicate assumed pre-instrumental warming of $0^{\circ} \mathrm{C}$ relative to 1850-1900 (solid), $0.1^{\circ} \mathrm{C}$ (dashed) and $0.2^{\circ} \mathrm{C}$ (dotted). Distributions in bottom panels show uncertainty in the observational estimate of warming from 1850-1900 to 1986-2005 (grey) and model distributions of 100 year mean temperatures in periods prior to 1800 relative to the 1850-1900 mean added to the mean warming from 1850-1900 to 1986-2005, using ALL forcings (red) and GHG forcings only (green), the purple line shows the equivalent 1720-1800 temperature range estimated by Hawkins et al8. 
Global temperature in 2080-2100
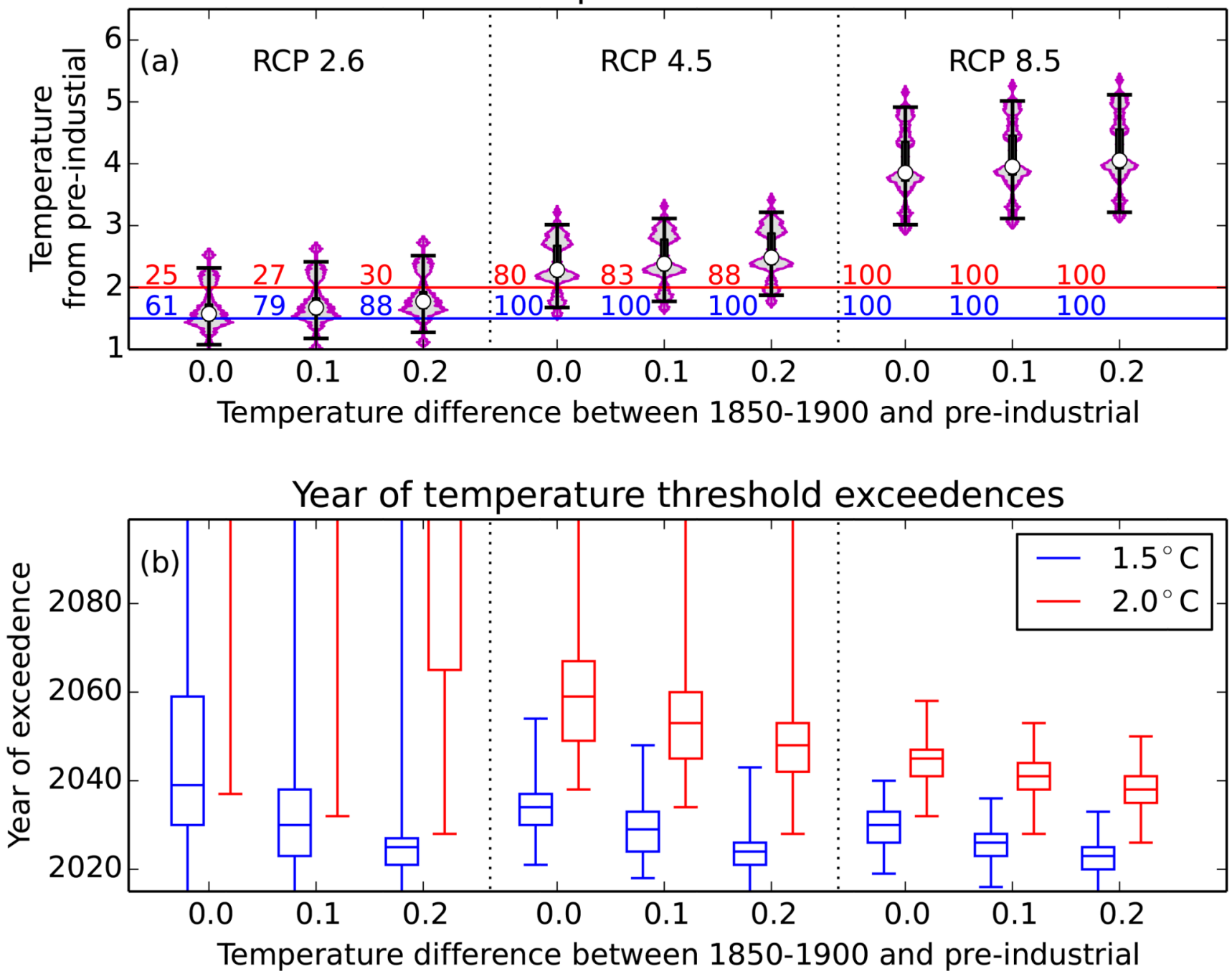

Figure 4. Probability distributions for mean temperatures and time of threshold exceedance. a) Model temperature projections. Model distribution (violin plot, purple line), 33-66\% range (thick black line) 5-95\% range (whiskers) and median value (white circle). Text gives probability of exceeding $1.5^{\circ} \mathrm{C}$ (blue) and $\left.2^{\circ} \mathrm{C}(\mathrm{red}), \mathrm{b}\right)$ Probability of threshold crossing year for $1.5^{\circ} \mathrm{C}$ (blue) and $2^{\circ} \mathrm{C}$ (red). 5-95\% range (whiskers), 33-66\% range (box) and median value (horizontal line). 